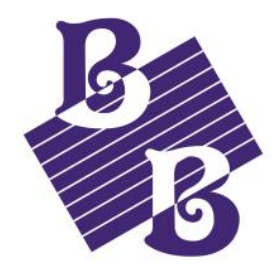

Biobacta

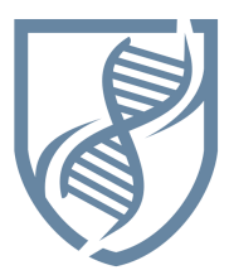

Journal of Bioscience and Applied Research WWW.JBAAR.ORG

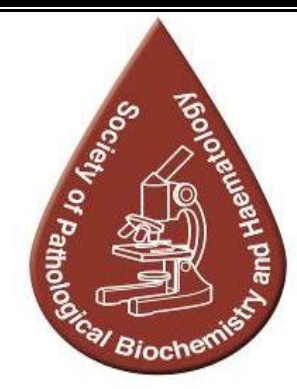

\title{
green synthesis and characterization of iron-oxide nanoparticles by guava aqueous leaves extract for doxorubicin drug loading
} Moustafa Hussein Moustafa $^{1 *}$, Rasha shams Al Din ${ }^{2}$

\author{
Biophysics Department, Medical research institute ${ }^{1,2}$ \\ (*Email: Moustafa-hm@alexu.edu.eg) \\ DOI: 10.21608/jbaar.2017.126138
}

\begin{abstract}
Green biosynthesis of iron oxide nanoparticles $\left(\mathrm{Fe}_{3} \mathrm{O}_{4}\right.$ $\mathrm{Nps}$ ) was carried out in one step. An aqueous extract of orange peels, green tea, and guava leaves was utilized as a precipitating agent for metal precursors. The guava leaves extract was the most powerful one. The shape and size of $\left(\mathrm{Fe}_{2} \mathrm{O}_{3} \mathrm{Nps}\right)$ were monitored by transmission electron microscopy. The existence of iron in the yield was studied by UV-visible spectroscopy. The stability of the particles was estimated by hydrogen peroxide reaction. The $\left(\mathrm{Fe}_{3} \mathrm{O}_{4}\right.$ $\mathrm{Nps})$ were incubated with human red blood cells( $\mathrm{R}$ $\mathrm{BCs})$. the osmotic fragility test for (R BCs) showed no significant shifting from the control. The loading of doxorubicin cytotoxic drug was primitively monitored by scanning electron microscopy for the further study plan.
\end{abstract}

Keywords: iron-oxide nanoparticles, green biosynthesis, doxocirobcin

\section{Introduction}

Iron-oxide nanoparticles (Fe3O4NPs) have become strong candidates for much biomedical application due to, their small sizes besides the magnetic properties (Monalisa $\mathrm{P}$ et al., 2013) ${ }^{1,2}$. It is important to choose the raw material for (Fe NPs) preparation otherwise the methods for the adjustable physical and chemical properties of interest. Among the methods of preparation for these (Fe NPs) coprecipitation, thermal decomposition sonochemical methods are the most. Besides electrochemical and green syntheses are introduced by many researchers (Akl M et al., 2012) ${ }^{3}$.
The chemical synthetic procedures generate hazardous byproducts that could affect the environment directly. Thus there is a great requirement for green chemistry that includes methods that are environment friendly ${ }^{1}$. Hence nowadays many researchers are diverting themselves towards biological systems mostly plants for nanoparticle synthesis as it is cost-effective and can be easily scaled up to be used for large-scale production(Iy-er A et al ., 2009) ${ }^{1,4}$. The cellular extracts from these biological organisms (such as plants and micro-organisms) can be used to synthesize nanoparticles of different sizes and chemical compositions as they contain certain oxidizing compounds like polyphenol which can reduce metal ion precursors whereas water-soluble heterocyclic components stabilize the metal nanoparticles formed. This Biosynthesis of metal nanoparticles extracted from different parts (mostly leaf) of the plant is the most effective process of synthesis at a very affordable $\operatorname{cost}^{1-5}$

Entrapping nanoparticles with drugs is a great challenge nowadays. FDA approved doxorubicin hydrochloride drug as liposome-based has been used for the treatment of cancer (Xu et al., 2013) ${ }^{6}$.In the current work, we utilize the aqueous Guava leaves extract to produce iron-oxide oxide nanoparticles. The shape and size of these Fe NPs are observed by Transmission electron microscopy. The Doxcirobcine drug was loaded on the prepared MNPs and the rate of drug loading efficiency was evaluated.

\section{Materials and Methods}

\section{Preparation of plant extract}

Fresh Leaves of guava, green tea, and orange plants were collected from the local markets in Alexandria city, Egypt the leaves were washed twice with distilled water after that they were left to dry. $200 \mathrm{mg}$ 
of dried leaves were squashed and incubated in 100 $\mathrm{ml}$ double-distilled water in a $250 \mathrm{ml}$ beaker overnight. The aqueous leaf extract was taken and the leaves debris was discarded. The leaves extract was centrifuged then filtered by Whatman filter paper twice to exclude any remnant debris. The clean aqueous extract was preserved at $-20{ }^{\circ} \mathrm{C}$ for further use.
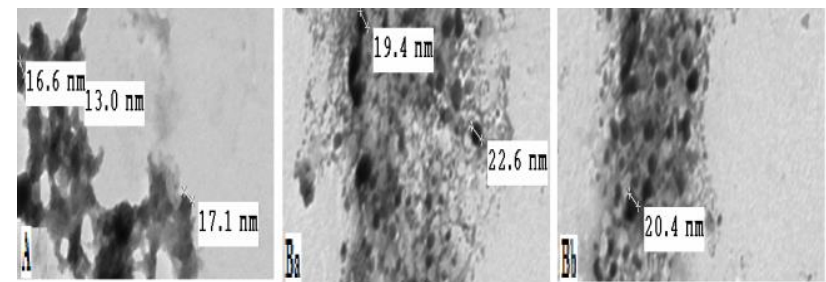

Figure 1: Scanning electron photographic images and corresponding approximate particle sizes, (A) for free $\mathrm{Fe}_{3} \mathrm{O}_{4}$, $(\mathrm{Ba}, \mathrm{Bb}) \mathrm{Fe}_{3} \mathrm{O}_{4}$-Doxo. Loaded particles.

\section{Characterization of iron-oxide nanoparticles}

\section{Ultraviolet-Visible absorption (UV-Vis)}

Ultraviolet-visible spectroscopy (UV-Vis) refers to absorption spectroscopy in the UV-Visible region. This means it uses light in the visible and adjacent (near-UV and near-infrared) ranges. The absorption in the visible range directly affects the perceived color of the chemicals involved. In this region of the electromagnetic spectrum, molecules undergo electronic transitions.

\section{Fourier transformer Infrared analysis (FT-IR)}

FTIR was used to identify the peak value of the functional groups of the active components by infrared irradiation. The sulfate group is responsible of the reduction of metal ions via oxidation of aldehyde groups in the molecules to carboxylic $\operatorname{acids}^{7,8}$. The UV Visible spectrum of Fe3O4-NPs in the aqueous guava extract is shown in. The two absorption peaks at wavelengths of $402 \mathrm{~nm}$ and 415 $\mathrm{nm}$ indicate the formation of iron nanoparticles

\section{Results and discussion}

\section{Determination of total antioxidants}

The total antioxidant activity (TAA) of plant leaves aqueous extract were determined by $\beta$-carotene bleaching method adopted from Kaur $\mathrm{C}$ et $\mathrm{al}^{9}$. Oxidation of the $\beta$-carotene emulsion was assessed by spectophotemeter at 10-min interval at $470 \mathrm{~nm}$. TAA was expressed as per cent $\beta$-carotene inhibition relative to control according to Equation 1

\section{TAA $=\frac{\text { Absorbance (control }- \text { sample) }}{\text { Abse }}$ \\ Absorbance of control (The total antioxidant activity (TAA) of plant leaves aqueous extract were determined by $\beta$-carotene bleaching method adopted from Kaur $C$ et al. Oxidation of the $\beta$ - carotene emulsion was assessed by spectophotemeter at 10-min interval at $470 \mathrm{~nm}$. TAA was expressed as per cent $\beta$-carotene inhibition relative to control according to Equation 1) \\ Synthesis of Fe NPs}

The (Fe2O3) were synthesized using a constant volume of the plant extract with ferrous sulfate solution $(2 \mathrm{mM})$, with concomitant stirring at room temperature. The mixture was sonicated to apart the plant debris. The appearance of dark color indicates the formation of (Fe3O4) nanoparticles Figure 1.

Table 1: The percentage of TAA in different green leaves extract included in the current work. The values expressed as mean \pm SD for duplicates p. $>0.05$.

\begin{tabular}{|c|c|}
\hline Leaves extract & (TAA) $(\mathbf{m g} / \mathbf{1 0 0 m l})$ \\
\hline Guava extract & $\mathbf{5 0} \pm 6$ \\
Green tea & $\mathbf{3 8} \pm 10$ \\
Orange leaves & $\mathbf{1 5} \pm 8$ \\
\hline
\end{tabular}

The preparation procedure was adopted from the previous work of (Akl M. Awwad et al., 2012 ${ }^{10}$ and

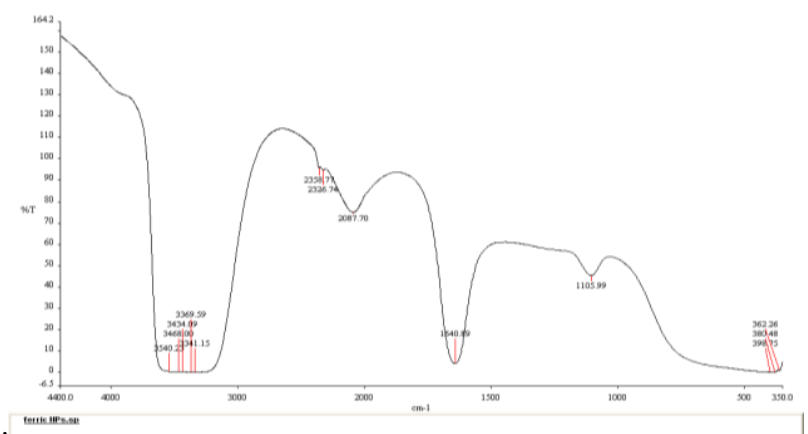

Figure 2: Outprint of FTIR representing the main peaks of functional groups of $\mathrm{Fe} 3 \mathrm{O} 4$

Harajyoti $\mathrm{M}^{11}$ et al). Ferrous sulphate solution of $2 \mathrm{~m}$ $\mathrm{M}$ concentration was $\mathrm{pH}$ was about 5.5 . a $100 \mathrm{ml}$ FeSO4 solution was taken in a $250 \mathrm{ml}$ conical flask to which $10 \mathrm{ml}$ of plant leaves extract was added with continuous shaking. The (Fe3O4 NPs) was formed by the appearance black color of the solution. The nanoparticles were then precipitated by centrifuging at $13,000 \mathrm{rpm}$ for $15 \mathrm{mins}$ and stored at $-4^{\circ} \mathrm{C}$ for further use. 


\section{Osmotic fragility test}

The fragility of red blood cells (RBCs) was estimated after incubation of the cells with iron-oxide nanoparticles. The osmotic fragility was adopted from H. A. Massaldi, et al incubated with BSR20 ul of.$^{12}$ ) different concentration of $\mathrm{Fe} 3 \mathrm{O} 4$ nanoparticles for about 6 hours at $37{ }^{\circ} \mathrm{C}$ was added to a serial dilution of normal physiological saline solution with different osmolality \% from the following Equation 2:

Hemolysis $\%=\frac{\text { absorbance of the test }}{\text { absorbance of complete hemolysis }} \times 100$ The fragility of red blood cells (RBCs) was estimated after incubation of the cells with iron-oxide nanoparticles. The osmotic fragility was adopted from H. A. Massaldi, et al ). $20 \mathrm{ul}$ of RBS incubated with different concentration of $\mathrm{Fe} 3 \mathrm{O} 4$ nanoparticles for about 6 hours at $37{ }^{\circ} \mathrm{C}$ was added to a serial dilution of normal physiological saline solution with different osmolality \% from the following Equation 2:

\section{DOXO drug loading to MNPs}

Loading procedure was adopted from (Davaran et al., 2012) $)^{13} .2 \mathrm{ml}$ of DOXO. was added to $1 \mathrm{gm}$ of dried MNPS. The mixture was stirring magnetically for 24 hours at room temperature the Doxo-loaded MNPs was separated with centrifugation for further analysis. The percent of Doxo.loading were deduced by the relation Equation 3

$$
\begin{aligned}
& \text { Doxo.loading efficiency }=\frac{\text { weight of } \text { Doxo. after incubation }}{\text { weight initial Doxo. }} \text { The percent of } \\
& \text { Doxo.loading were deduced by the relation Equation } 3
\end{aligned}
$$

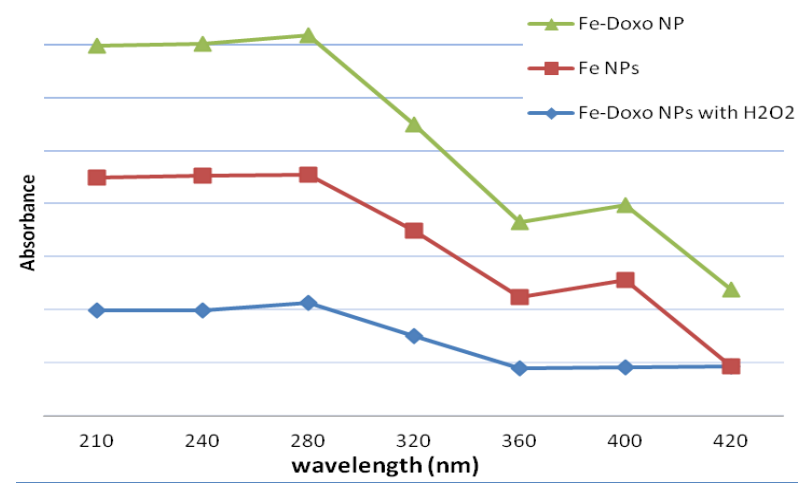

Figure 3: Graphic distribution of absorbance versus the corresponding wavelength showing the maximal absorbance peak.

\section{$\mathrm{Fe}_{3} \mathrm{O}_{4} \mathrm{NPs}-\mathrm{H}_{2} \mathrm{O}_{2}$ oxidation}

Nanoparticle resistance to oxidation was measured by UV-vis before and after the addition of $100 \mu 1$ of $30 \%$ $\mathrm{H}_{2} \mathrm{O}_{2}$ to $5 \mathrm{ml}$ nanoparticle suspension for five minute. as shown in Figure 3, there is no shift in absorbance peak neither plain Fenps or Fe-Doxo Nps s $^{3,14}$

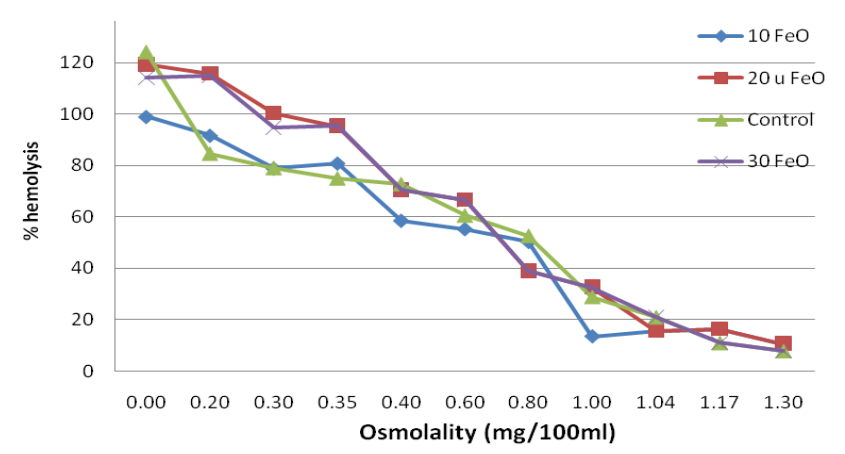

Figure 4:graphical representation of hemolysis percentage of $\mathrm{RBCs}$ versus concentration rang of normal saline for control (plain RBCs) and RBCs incubated with $\mathrm{Fe} 3 \mathrm{O} 4$ of $0.1,0.2$, and $0.3 \% \quad(\mathrm{v} / \mathrm{v})$.the tests were replicated twice represented as mean $\pm \mathrm{SD}$ and pvalue $>0.05$.

The peaks at 1540 and $1105 \mathrm{~cm}^{-1}$ are attributed to the asymmetric and symmetric stretching vibration of COO- ${ }^{10}$. The band at $1105.99 \mathrm{~cm}-1$ can be assigned to the symmetric $\mathrm{C}-\mathrm{O}$ vibration associated with $\mathrm{aC}-\mathrm{O}-$ $\mathrm{SO} 3$ group . In addition, signals at $3698 \mathrm{~cm}-1(\mathrm{OH}$ stretching) and 2358 ad $23269 \mathrm{~cm}^{-1}$ (CH stretching) were also observed ${ }^{10,15}$.

The presence of magnetite nanoparticles can be seen by two strong absorption bands at around 398 , 380, and $362 \mathrm{~cm}-1$ which Figure 2, corresponding to the $\mathrm{Fe}-\mathrm{O}$ stretching band of bulk magnetite $(\mathrm{Fe} 3 \mathrm{O} 4)^{16}$. These results revealed that the $\mathrm{C}=\mathrm{O}$ groups were bonded on the magnetite particle surface. Overall the observation confirms the presence of organic compounds in guava leaf extract, which acts as a reducing agent and stabilizer for magnetite nanoparticles. These results are in co-ordinance with the results of Mahnaz M et al. ${ }^{10,7}$

The osmotic fragility results are represented in Figure 4. there is no significant skewness of the graph and control graph without $\mathrm{Fe} 3 \mathrm{O} 4 \mathrm{NPs}$.this finding may support that $\mathrm{Fe} 3 \mathrm{O} 4 \mathrm{NPs}$ have no osmotic stress on the RBCs integrity under these conditions.

\section{Acknowledgement}

From my deep heart I would like to appreciate the valuable advices and scientific guidance of Dr. Mohamed Abdel Aziz AlBelbesy in the experimental design of this work.

\section{References}

1 Demir, A., Topkaya, R. and Baykal, A. (2013). Green synthesis of superparamagnetic $\mathrm{Fe} 3 \mathrm{O} 4$ nanoparticles with maltose: Its magnetic investigation. Polyhedron, 65, pp.282-287. 
2 J.Ngenefeme, F., J. Eko, N., D. Mbom, Y., D. Tantoh, N. and M. Rui, K. (2013). A One Pot Green Synthesis and Characterisation of Iron Oxide-Pectin Hybrid Nanocomposite. Open Journal of Composite Materials, 03(02), pp.30-37.

3 M. Awwad, A. and M. Salem, N. (2013). A Green and Facile Approach for Synthesis of Magnetite Nanoparticles. Nanoscience and Nanotechnology, 2(6), pp.208-213.

4 Wang, Z., Zhu, H., Wang, X., Yang, F. and Yang, $X$. (2009). One-pot green synthesis of biocompatible arginine-stabilized magnetic

nanoparticles. Nanotechnology, 20(46), p.465606.-

5 Mahdavi, M., Namvar, F., Ahmad, M. and Mohamad, R. (2013). Green Biosynthesis and Characterization of Magnetic Iron Oxide (Fe3O4) Nanoparticles Using Seaweed (Sargassum muticum) Aqueous Extract. Molecules, 18(5), pp.5954-5964.

6 XU, L., LI, H., WANG, Y., DONG, F., WANG, H. and ZHANG, S. (2013). Enhanced activity of doxorubicin in drug resistant A549 tumor cells by encapsulation of P-glycoprotein inhibitor in PLGAbased nanovectors. Oncology Letters, 7(2), pp.387392.

7 Mahdavi, M., Namvar, F., Ahmad, M. and Mohamad, R. (2013). Green Biosynthesis and Characterization of Magnetic Iron Oxide (Fe3O4) Nanoparticles Using Seaweed (Sargassum muticum) Aqueous Extract. Molecules, 18(5), pp.5954-5964

8 Von White, G., Kerscher, P., Brown, R., Morella, J., McAllister, W., Dean, D. and Kitchens, C. (2012). Green Synthesis of Robust, Biocompatible Silver Nanoparticles Using Garlic Extract. Journal of Nanomaterials, 2012, pp.1-12.

9 Kaur, C. and Kapoor, H. (2002). Anti-oxidant activity and total phenolic content of some Asian vegetables. International Journal of Food Science and Technology, 37(2), pp.153-161.

10 M. Awwad, A. and M. Salem, N. (2013). A Green and Facile Approach for Synthesis of Magnetite Nanoparticles. Nanoscience and Nanotechnology, 2(6), pp.208-213.

11 Venkatpurwar, V. and Pokharkar, V. (2011). Green synthesis of silver nanoparticles using marine polysaccharide: Study of in-vitro antibacterial activity. Materials Letters, 65(6), pp.999-1002.
12 H. A. Massaldi, G. V. Richieri, H. C. Mel.(1988) . Osmotic fragility model for red cell Populations. BIOPHYS. J.57,pp301-308.

13 Davaran, S., Asgari, D., Davaran, S., Akbarzadeh, A., Zarghami, Mikaeili, H. and Mohamad, R. (2012). Preparation and in vitro evaluation of doxorubicinloaded $\mathrm{Fe} 3 \mathrm{O} 4$ magnetic nanoparticles modified with biocompatible copolymers. International Journal of Nanomedicine, p.511.

14 Von White, G., Kerscher, P., Brown, R., Morella, J., McAllister, W., Dean, D. and Kitchens, C. (2012). Green Synthesis of Robust, Biocompatible Silver Nanoparticles Using Garlic Extract. Journal of Nanomaterials, 2012, pp.1-12

15 Sangeetha, N., Manikandan, S., Singh, M. and K. Kumaraguru, A. (2012). Biosynthesis and Characterization of Silver Nanoparticles Using Freshly Extracted Sodium Alginate from the Seaweed Padina tetrastromatica of Gulf of Mannar, India. Current Nanoscience, 8(5), pp.697-702.

16 Qiu, X. (2010). Synthesis and characterization of magnetic nano particles. Chinese Journal of Chemistry, 18(6), pp.834-837. 